\title{
História da música: obras e fatos que podem transversalizar com o cotidiano escolar
}

\author{
Music history: works and facts that can cross-reference with everyday school life \\ Cristina Rolim Wolffenbüttel ${ }^{1 *}$
}

RESUMO

Este é um ensaio que trata da possibilidade da inserção de aspectos da música clássica e da história da música na educação básica. Apresenta elementos da vida e obra de dois compositores da chamada música clássica, Johann Sebastian Bach e Ludwig van Beethoven, transversalizando-os ao cotidiano das pessoas, e propondo sua articulação ao trabalho pedagógico-musical. Nesse sentido, são mencionados aspectos biográficos e composicionais de ambos os compositores, cuja importância histórica e musicológica pode auxiliar no desenvolvimento do ensino de música na educação básica. Relata, também, uma oficina destinada à formação de professores, ofertada para professores da Rede Municipal de Ensino de Porto Alegre (Rio Grande do Sul), na qual foram desenvolvidas atividades, partindo de Bach e Beethoven, com o propósito de unir a música clássica e a história da música nos planejamentos pedagógicos em espaços escolares. Como resultados, observou-se que há muitas possibilidades de introdução de elementos biográficos de compositores, o que pode potenciar e fundamentar o ensino e a aprendizagem de música na escola.

Palavras-chave: Música clássica; Música na escola; Bach; Beethoven; Biografia.

\section{ABSTRACT}

This is an essay that deals with the possibility of inserting aspects of classical music and the history of music in basic education. It presents elements of the life and work of two composers of the so-called classical music, Johann Sebastian Bach and Ludwig van Beethoven, transposing them to people's daily lives, and proposing their articulation to the pedagogical-musical work. In this sense, biographical and compositional aspects of both composers are mentioned, whose historical and musicological importance can help in the development of music teaching in basic education. It also reports a workshop aimed at training teachers, offered to teachers of the Municipal Education Network of Porto Alegre (Rio Grande do Sul), in which activities were developed, starting from Bach and Beethoven, with the purpose of uniting classical music and the history of music in pedagogical planning in school spaces. As a result, it was observed that there are many possibilities of introducing biographical elements of composers, which can enhance and support the teaching and learning of music at school.

Keywords: Classical music; Music at school; Bach; Beethoven; biography.

\footnotetext{
${ }^{1}$ Programa de Pós-Graduação em Educação - Mestrado Profissional, Universidade Estadual do Rio Grande do Sul.

* cristina-wolffenbuttel@uergs.edu.br
} 


\section{INTRODUÇÃO}

Abordagens educacionais procuram entender o cotidiano escolar de uma forma mais ampla, considerando a diversidade, a cultura experiencial, a pesquisa e o trabalho escolar como um cruzamento das culturas (PÉREZ GÓMEZ, 2001, p. 16). Neste sentido, entende-se como cultura o

[...] conjunto de significados, expectativas e comportamentos compartilhados por um determinado grupo social, o qual facilita e ordena, limita e potencia os intercâmbios sociais, as produções simbólicas e materiais e as realizações individuais e coletivas dentro de um marco espacial e temporal determinado. A cultura, portanto, [como] o resultado da construção social, contingente às condições materiais, sociais e espirituais que dominam um espaço e um tempo. (PÉREZ GÓMEZ, 2001, p. 17).

Percebe-se, assim, a possibilidade de uma aprendizagem significativa, na medida em que se busca uma interlocução entre as diversas culturas existentes na escola e a função educativa inerente a esse processo. Os variados elementos subterrâneos, tácitos e imperceptíveis que fazem parte do cotidiano escolar influenciam, decisivamente, na socialização e educação. Assim, é importante que a escola reflita sobre si mesma, para poder se oferecer como plataforma educativa, a qual tenta aclarar o sentido e os mecanismos através dos quais exerce a ação da influência sobre as novas gerações (PÉREZ GÓMEZ, 2001).

Sob este ponto de vista, é oportuno pensar em ações educativas que considerem a ampla inclusão dos aspectos da cultura, procurando gerar questionamentos e buscando posturas dialéticas e dialógicas diante das representações sociais relacionadas à construção do conhecimento, e isso, em todas as faixas etárias e níveis de ensino. Neste sentido, entende-se que a inserção da música nas escolas possa potencializar as ações educativas que incluam os múltiplos aspectos da cultura, entendendo a heterogeneidade de tipos e gêneros musicais, como a música popular, folclórica, clássica, dentre tantas possibilidades.

A música clássica, em particular, é o foco deste artigo, materializando-se na possibilidade da introdução dos conteúdos da história da música em propostas pedagógico-musicais da educação básica. Sabe-se que, atualmente, há uma opção pela 
expressão música de concerto, inclusive ao invés de música erudita ou clássica. A este respeito, Nogueira (2012) preconiza:

A expressão "música erudita", pouco utilizada fora do Brasil, pode se referir a composições em que se exige, tanto dos músicos quanto do público, ilustração, ou seja, um tipo de erudição em geral adquirida pela leitura, cursos especializados, audições comentadas de gravações e o hábito de frequentar salas de concerto. "Erudito" tem como antônimo a palavra popular e, mais etimologicamente, significa o oposto de rude ou não cultivado. A palavra "clássico", por sua vez, remete-se a ideias ou obras paradigmáticas que servem de modelo para outras, ou seja, dignas de serem imitadas. (NOGUEIRA, 2012, p. 122).

Conforme o autor, o que tem sido mais empregado é o termo música de concerto, “provavelmente por seu sentido um pouco mais objetivo ao indicar o repertório específico apresentado em salas de concerto" (NOGUEIRA, 2012, p. 122).

Mojola (2018), porém, argumenta a favor do vocábulo "clássica". Segundo ele, sua opção deu-se

[...] porque, além de consagrado pelo uso, o termo ganha cada vez mais força, superando expressões como música erudita ou música de concerto. Clássica, nesse caso, refere-se ao tipo de música veiculada em eventos (concertos ou recitais) realizados em teatros convencionais ou espaços de perfil semelhante. O repertório executado também delimita essa definição; no entanto, a diferença entre um concerto reconhecido tradicionalmente como clássico e outro, no qual essa classificação pode ser questionada, é cada vez menos nítida. (MOJOLA, 2018, p. 61).

Portanto, concordando com Mojola (2018) e, considerando-se as finalidades deste artigo, optou-se pela utilização da denominação música clássica. Até porque, muitas vezes, no linguajar coloquial e cotidiano, é assim que as pessoas têm denominado este tipo de música.

Normalmente, a música clássica é tratada como um tipo mais elaborado, erudito, em que cada cultura possui a sua, e não pertence a nenhuma espécie de folclore ou tradição; é uma música dita estudada e bem mais elaborada. Conforme Kennedy (2013), a música clássica é de uma natureza ordenada, com qualidades como clareza e equilíbrio, e enfatizando a beleza formal, ao invés da expressão emocional. No entanto, não se deve pensar que falte emoção nesta música. Geralmente, é considerada de valor permanente, não efêmero. Oposta à música popular, no que diz respeito ao modismo, por exemplo. 
Tendo em vista o exposto anteriormente, é importante e, sobretudo, significativo, pensar em uma abordagem em história da música na escola que permita interlocuções entre a vida das pessoas e os fatos musicais transcorridos ao longo desta trajetória factual. Freire (1994) explica que a "História é um relato interpretativo, feito por um sujeito histórico, e necessariamente impregnado dos significados e percepções de sua época”. Assim, considerar esses significados e percepções no planejamento do ensino de música pode aproximar estudantes do aprendizado dos aspectos histórico-musicais, a partir do entrelaçamento de tudo o que envolve a vida e a obra de compositores e musicistas, em geral.

Nesse sentido, uma das possibilidades pode ser o conhecimento de aspectos musicológicos e biográficos que contribuíram para o surgimento de determinadas obras musicais. É bem sabido que a educação musical no ambiente escolar não se constitui, puramente, de aulas que enfoquem a história da música. Em propostas pedagógicomusicais é necessário desenvolver as diversas potencialidades dos estudantes, como atividades de composição, execução, apreciação musical (SWANWICK, 2003). Todavia, esta é uma dentre as tantas possibilidades que podem fazer parte do cotidiano do ensino de música na escola.

Pensando nesses aspectos, relembro uma experiência muito interessante e inusitada pela qual passei há algum tempo atrás. Em uma de minhas atividades na assessoria em música na Secretaria Municipal de Educação de Porto Alegre, Rio Grande do Sul (SMED-POA/RS), fui desafiada a realizar uma oficina de música, com foco na história da música, para professores da Rede Municipal de Ensino de Porto Alegre (RMEPOA/RS). Até este ponto, tudo certo. Sem problemas. No entanto, o ponto que se apresentou como provocador foi a data proposta para tal formação: uma noite de 12 de junho, justamente no dia dos namorados!

Não é necessário dizer a apreensão que fui acometida, ao julgar ser um momento em que pouca ou, talvez, nenhuma presença tivesse na oficina. Porém, para a grata surpresa, todos os participantes compareceram ao evento. Ainda assim, contudo, havia um desafio: aguçar a curiosidade dessas pessoas. Esta preocupação, entretanto, já havia povoado os pensamentos, no propósito de tornar não somente atrativo o momento - dadas as circunstâncias - mas, também, elucidativo e esclarecedor, considerando-se o objetivo de refletir sobre modos de inserção de aspectos da história da música, e experienciandoos - com o foco na música clássica - nos planejamentos pedagógico-musicais. 
Esse interesse foi alcançado, a partir de aspectos da história da música, incluindo os musicológicos e os biográficos, os quais serão abordados, a seguir. Nesse sentido, são apresentados alguns dos aspectos desenvolvidos na oficina, considerando-se a história da música, obras e fatos da vida que podem transversalizar com o cotidiano escolar. Para tanto, optou-se por focar a vida e a obra de compositores cujas obras são conhecidas da maioria das pessoas, apesar de que, algumas vezes, não percebam isso.

A respeito do enfoque nas biografias, entende-se sua importância e o surgimento de inúmeras possibilidades pedagógicas e para a própria vida das pessoas. Bach Júnior (2019, p. 237) argumenta que o "trabalho biográfico envolve uma gama temática muito ampla. Na formação de educadores, por exemplo, temas relacionados à educação, ao desenvolvimento humano e ao aprendizado são privilegiados". A par disso, e conforme o autor, com o trabalho biográfico:

[...] indivíduo pode acessar sua potencialidade autotransformativa no trabalho biográfico em diferentes âmbitos: a biografia do processo educacional, a biografia do aprendizado, a biografia do desenvolvimento próprio, a biografia das ameaças e impasses vividos, a biografia da evolução da personalidade. (BACH JÚNIOR, 2019, p. 237).

Com base nestes pressupostos, optou-se pela abordagem biográfica, ao realizar a oficina. E, assim, os compositores escolhidos foram Bach e Beethoven. Destaca-se que esta escolha teve como base uma consulta prévia aos participantes da oficina, a fim de saber quais os nomes de compositores que lhes vinham à mente, que para eles fossem representativos da música clássica, e que tivessem interesse em conhecer mais. Salientaram-se, como os mais referidos, Bach e Beethoven.

Para compartilhar os aspectos da contextualização feita sobre ambos os compositores, é apresentada, a seguir, uma síntese da vida e obra de cada um deles.

\section{Bach e Beethoven: amores e superações}

Johann Sebastian Bach nasceu em 21 de março de 1685, vindo a falecer em 28 de julho de 1750, em Eisenach, na Alemanha (GALWAY, 1987). Na ocasião em que Bach viveu, os compositores e os músicos em geral tinham, talvez, apenas duas possibilidades de atuação profissional. Uma delas consistia no trabalho musical - composição e/ou 
execução instrumental - para a igreja (luterana e católica). A outra possibilidade era através da elaboração de composições musicais, ou mesmo da atuação em conjuntos instrumentais.

Ser músico no período barroco não equivalia a ser uma entidade à parte do comum dos mortais. Ele ocupava a posição de um artesão, com aptidões requeridas e valorizadas pela comunidade. Se talentoso, agiria como um ourives, ou um sapateiro, passando sua profissão aos descendentes, como fez Bach... (NOVA CULTURAL, 1988, p. 61).

Bach atuou nos dois modos sendo, inclusive, notável como organista e cravista.

Inicialmente, quando se pensa nos nomes dos grandes compositores, vem à mente uma imagem de boa e tranquila vida, sem as atribulações que, normalmente, assolam a existência da sociedade como um todo. Mas, a partir do conhecimento sobre como efetivamente era o cotidiano de muitos dos grandes compositores, e o de Bach, em especial, as concepções transformam-se inexoravelmente. A própria fama e a glória chegaram-lhe muito tardiamente. Conforme Gago (1995), sua biografia é uma das mais desconhecidas dentre os grandes compositores da história da música ocidental, e a envergadura de sua produção musical continua sendo um mistério até a atualidade.

Outro ponto importante a ser tratado sobre Bach e que, talvez, não se conheça, é que ele passou por inúmeros reveses na vida, sendo um deles a cegueira. Sabe-se que Bach passou o final de sua vida inteiramente cego (MIRANDA C., 2019). Estudos indicam que, provavelmente, Bach fosse míope, o que pode ser percebido a partir de seus retratos, que foram pintados à época, e que mostram seus olhos estreitos e o cenho franzido, sinal de que estava forçando a visão. Sabe-se, também, que ele passava muito tempo lendo, escrevendo e compondo, e isso desde a infância, o que pode ter majorado a situação. Em 1750 o caso agravou-se, e Bach passou a ter dores no globo ocular, o que fez com que sua família procurasse por auxílio médico. Vários tratamentos foram empregados, mas, ao final, ele acabou ficando completamente cego, e falecendo em seguida (MIRANDA C., 2019). A par de tudo isso, é desnecessário dizer o quanto Bach trabalhou. Inúmeras foram suas composições, uma obra vasta.

Ao mencionar seu viés composicional, vale salientar que muitas de suas músicas aparecem em diversos veículos de comunicação, tais como propagandas em rádio e televisão, bem como nas inúmeras mídias. Outra forma de veiculação se dá nas redes sociais, através de jogos de computador, na Internet, bem como em aparelhos celulares, 
apenas para citar algumas das modalidades em que as músicas de Bach têm sido veiculadas. Dentre suas importantes obras, destaca-se "O Cravo Bem Temperado", que consiste em 48 prelúdios e fugas, gêneros musicais cujo ápice deu-se em sua época de atuação. Uma curiosidade desta obra reside no fato de o compositor propor-se a elaborar um trabalho dentro de um sistema que estava se estruturando na ocasião, o sistema temperado ${ }^{2}$. Isso foi revolucionário e transformou radicalmente as músicas e os modos composicionais da época.

Neste ponto, pensa-se no indivíduo Bach, com seus problemas crescentes de cegueira, e tendo de cumprir as inúmeras incumbências profissionais. Este aspecto pode suscitar reflexões e, assim, transversalizar com um dos aspectos que crescentemente têm adentrado às escolas e os planejamentos escolares: as questões da inclusão. É possível e pertinente, ao organizar os planejamentos pedagógico-musicais e, a partir da inserção da música clássica e da história da música, incluir discussões, menções e diversas atividades, a partir da escuta de obras de Bach e, ao longo do trabalho, fazer referências à sua biografia, trazendo relatos históricos de suas dificuldades visuais. Frisa-se que, muitas vezes, quando as pessoas realizam audições musicais, não pensam ou não têm conhecimento sobre a biografia dos musicistas. Esta conexão vai ao encontro do que tem sido preconizado na atualidade, no que diz respeito à inclusão na educação, que aproxima nossa vida da vida dos grandes compositores, alertando-nos que eles eram, acima de tudo, pessoas que viviam num tempo e num espaço. E, ao estabelecer esta conexão, pode ser um elo de sedução para a audição musical, para o convite à contemplação e, neste caso, em especial, à apreciação de músicas clássicas. Reflete-se, portanto, e a partir de Bach Júnior (2019), que educação

[...] é transformação da subjetividade com propósitos estipulados por uma teoria ou método pedagógico, por intenções pedagógicas orientadas segundo os parâmetros sociais e culturais de uma época. A educação biográfica é autoeducação, o próprio sujeito se transforma tendo como parâmetro sua experiência de vida para corrigir rotas, superar impasses e reformular suas tendências individuais. $\mathrm{O}$ trabalho biográfico é uma dinamização das reflexões sobre o viver, com o intuito de levantamento de dados, percepção de padrões existenciais, reconhecimento do que foi ou vem sendo típico em sua caminhada existencial. (BACH JÚNIOR, 2019, p. 235).

\footnotetext{
$2 \mathrm{O}$ temperamento pode ser explicado como a forma pela qual os intervalos entre as notas musicais são distribuídos na escala, de modo que a música soe afinada em todos os tons.
} 
Nessa perspectiva, se fôssemos apontar características em Bach, uma delas poderia ser sua inserção no contexto histórico em que vivia. Ele foi, efetivamente, um homem de seu tempo, e esteve atento e informado sobre todas as novidades que surgiam ao seu redor. Outrossim, grande parte de sua obra consegue "escapar à mera contingência histórica e elevar-se acima dela" (GAGO, 1995, p. 8).

Outra obra monumental de Bach é "A Arte da Fuga", composta com a intenção de reunir exemplos e técnicas de contraponto. Esta obra é um conjunto de fugas com diferentes formas, mas com o mesmo tema básico. Infelizmente, essa composição ficou inacabada, pois o compositor veio a falecer, como mencionado, em 1750, dois anos depois de iniciá-la. Em sua última - e inacabada - fuga, Bach utilizou seu sobrenome como tema. Em música, as letras $b, a, c, h$ são as notas si bemol, lá, dó, si, respectivamente (ZAHAR, 1985).

Muitas versões dessas obras de Bach foram feitas para diversos instrumentos e conjuntos instrumentais, inclusive transformando-as para o gênero Rock. Quem sabe, até possam existir exemplos em Rap, Funk, e tantos outros gêneros musicais da atualidade! Isso dá uma dimensão da atualidade de Bach, o que pode ser analisado a partir da própria inserção do compositor em seu tempo, e que foi comentado anteriormente. Apesar de tantos séculos terem se passado, sua obra continua atual. Essa é uma das tantas possibilidades de transversalização de conteúdos de outrora com os da atualidade, e que podem integrar os planejamentos das aulas de música na escola.

Outras dimensões de análise sobre Johann Sebastian Bach podem ser aquelas que dizem respeito à sua própria vida, apesar de que, em seu caso, vida e obra se confundem. Um dado que frequentemente espanta as pessoas é que Bach teve uma prole de 20 filhos! Deve-se esclarecer que ele contraiu matrimônio duas vezes. Com a primeira esposa, Maria Bárbara, casou-se no ano de 1707, constituindo uma família de sete filhos ao longo dos 13 anos que conviveram. Porém, durante uma viagem, subitamente Maria Bárbara adoeceu, vindo a falecer logo em seguida. Em 1721, Bach conheceu Anna Magdalena, cantora, cujo pai era trompetista na corte. Casaram-se e, ao todo, o casal teve mais treze crianças.

Contam os biógrafos de Bach que Anna Magdalena revelou-se uma companheira adorável para o compositor, tanto que uma de suas obras mais conhecidas, O Livro de Anna Magdalena Bach, foi um trabalho elaborado para auxiliar sua esposa no aprendizado 
do cravo. Algumas de suas demonstrações de amor podem ser reveladas no registro do diário de Anna Magdalena:

Quando envelheci e minhas faces se enrugaram e meus cabelos se tornaram grisalhos, ele nem pareceu dar por isso. Somente uma vez me fez esta observação: Teus cabelos, que resplandeciam como o sol, têm agora a claridade da lua. É uma luz bem preferível para o par de namorados que somos. Mas inda que venhas a ter 20 filhos, parecerás sempre aos meus olhos como no dia de nossas núpcias! (PINTO, s/d, p. 161).

Ao final de sua vida, o compositor teve Anna Magdalena ao seu lado. Enquanto o pastor luterano falava sobre a morte do compositor, sua viúva curvava a cabeça. Pela mente de Anna Magdalena Bach, que mais tarde escreveria a biografia do marido, repassavam cenas de uma vida dedicada à arte. Sobre a ocasião, escreveria mais tarde: "Meu marido, meu grande homem, que canta agora diante do Senhor do Céu. Não tenho mais nenhuma razão para ficar neste mundo: minha verdadeira existência desapareceu com Sebastian. O tempo pesa-me longe dele" (PINTO, s/d, p. 161).

Após tantos anos passados de seu falecimento, a magnífica obra continua a ser reconhecida como uma das mais importantes da história da música. E, nesse sentido, como um conhecimento relevante a entrar no âmbito escolar, é fascinante que sua produção possa resultar num conhecimento significativo e prazeroso. Portanto, os aspectos da vida e da obra do compositor podem ser transversalizados, não como simples conhecimentos enciclopédicos, ou puras curiosidades, mas como elementos significativos, que auxiliem aos alunos e às pessoas em geral a perceberem que os compositores, também constituem suas vidas de diversos modos, e que a dita "vida das pessoas comuns" pode se assemelhar, em muito, ao cotidiano dos chamados grandes mestres. Ademais, saber que Bach e outros artistas viviam integrados à sua época, pode dar uma dimensão mais humana aos artistas, à arte e às obras resultantes desse contexto. Talvez este tipo de conhecimento possa aproximar os envolvidos nesse processo.

Muitos são os caminhos para a apreciação de obras de Johann Sebastian Bach. Como sugestão, pode-se optar por realizar uma audição firmando-se como ponto de partida os gêneros musicais, e tendo como base a música sacra, música de orquestra, música de câmara e música para teclado: 
Música sacra: Paixão Segundo São João (1724); Paixão Segundo São Mateus (1727); Oratório de Natal (1734); Missa em si menor (1749); Magnificat (1723); mais de 200 cantatas de igreja, incluindo as obras Cantata do Café (1735), Cantata dos Camponeses (1742).

Música de orquestra: Concertos Brandenburgo (1721); dois concertos para violino em lá menor, mi maior (1717-23); Concerto para violino, em ré menor (1723); Concertos para cravo (1738); oito concertos para cravo (ré menor, mi maior, ré maior, lá maior, fá menor, fá maior, sol menor, ré menor); três concertos para dois cravos (dó menor, dó maior, dó menor); dois concertos para três cravos (ré menor, dó maior); um concerto para quatro cravos (lá menor); quatro suítes para orquestra em dó maior, si menor (com flauta), ré maior, ré maior.

Música de câmara: 6 sonatas e partitas para violino (1720); 6 sonatas para violino e cravo (1717-23); 6 suítes para violoncelo (1720); Oferenda musical (1747); 7 sonatas para flauta, 3 sonatas para viola da gamba.

Música para teclado: 7 tocatas (1708-1710); Orgelbuchlein (Pequeno Livro do Órgão, 1717); Fantasia cromática e fuga, em ré menor (1720); O Cravo bem Temperado (1722-1742); Suítes Francesas (1722); Suítes Inglesas (1724-1725); Suítes Alemãs (1726-1731); 15 invenções, 15 sinfonias (1723); 6 Partitas (1731); Concerto Italiano (1735); Variações Goldberg (1741); A Arte da Fuga (1745-1750). (COLEÇÃO FOLHA DE MÚSICA CLÁSSICA, 2022).

Lopez (1995), ao tratar de Johann Sebastian Bach, resume sua importância para a história da música. Para o historiador, foi o

[..] imenso valor da obra de Bach que fez com que ela fosse resgatada do esquecimento para o reconhecimento que não teve em seu tempo. Atualmente, ninguém discute que Bach é o maior compositor do barroco, integrante de um grupo seleto numa imensa galeria de criadores de formas, a maioria deles constituída de burocratas da arte, cuja produção não se elevou acima dos modismos e rotinas de uma época, sucumbiu na vala comum dos trabalhos precocemente superados por seu valor efêmero. (LOPEZ, 1995, p.142-143).

Além de Bach, outro compositor escolhido para trabalhar na oficina foi Ludwig van Beethoven. Nascido em 1770, na cidade de Bonn, Alemanha, à semelhança de Bach, Beethoven também descendia de uma família de músicos. Seu pai, Johann van Beethoven, era músico, e trabalhava para o príncipe local. Ainda na época de Beethoven perdurava a forma de trabalho e as relações profissionais com as quais Bach também conviveu. Ou o trabalho era para a corte ou para a igreja. Somente mais tarde, principalmente com Mozart, os artistas começaram a produzir suas obras, sem estarem diretamente atrelados aos desejos e encomendas do clero ou da nobreza. 
De ascendência holandesa, o músico Johann, que já havia perdido vários filhos, só tinha uma ambição: que seu filho Ludwig fosse um gênio musical, tal como havia ocorrido em anos anteriores com Wolfgang Amadeus Mozart. Este foi um dos grandes problemas pelos quais Beethoven passou, pois, apesar de sua grande musicalidade e de amar profundamente a música, tudo para ele sempre foi resultante de muito trabalho, o que não era compreendido, tampouco tolerado por seu pai.

Alcoólatra e músico frustrado, Johann obrigava seu filho, Ludwig, a acordar muito cedo, e a estudar piano desde a madrugada. Além de tudo, foram muitas as surras sofridas por Beethoven, originadas de seu pai, em virtude da embriaguez.

Quando contava com 13 anos de idade, Beethoven foi obrigado a abandonar a escola e a trabalhar, pois problemas com o alcoolismo, de seu pai, avançaram muito. Destarte, começou o trabalho profissional de Beethoven, porém, sempre ligado ao fazer musical, atuando como organista de teatro e professor de música. Os feitos musicais foram inúmeros. Chegou a estudar com outro grande compositor, Haydn, que teve muita influência em seu futuro trabalho. Em outra ocasião chegou a encontrar Mozart, mas não chegou a render muitos frutos. Aos poucos, Beethoven iniciava a ser conhecido nos salões aristocráticos de Viena, local em que a vida musical fluía com muita intensidade na época.

Ele leva a vida de um jovem músico de corte. Tem catorze anos. A dupla tendência do seu caráter se afirma: é alegre, sente um imenso júbilo de existir, gosta de tocar música, dos ditos chistosos, da liberdade; mas também da solidão, dos longos momentos de meditação e de devaneio melancólico, disposições acentuadas pelo peso da atmosfera familiar. (FAUCONNIER, 2012, p. 21).

Em 1797, todavia, Beethoven começou a sentir os primeiros sintomas da enfermidade que acabaria o levando à surdez progressiva. A respeito de sua doença, Beethoven chegou a escrever a Wegeler, com muita tristeza, em 29 de junho de 1801, relatando problemas em seus ouvidos:

Posso lhe dizer que vivo uma vida miserável. Há quase dois anos evito encontros em sociedade, pois não posso dizer às pessoas: sou surdo. Se eu tivesse outra profissão, ainda seria possível; mas na minha é uma situação terrível. E o que diriam meus inimigos, que não são poucos? (FAUCONNIER, 2012, p. 53). 
Em 1818 Beethoven estava absolutamente surdo. No período que antecedeu a completa surdez, ele passou por problemas de depressão que, inclusive, afetaram sua produção musical. À época era denominada melancolia ou mal do século. Foi motivo de muitos suicídios na população em geral. E os artistas e musicistas não passaram incólumes. Em 1812, sobre seu estado, Beethoven escreveu em seu diário:

\begin{abstract}
Resignação, resignação profunda à tua sorte! Somente ela te permitirá aceitar os sacrifícios que o "serviço" exige. Oh, luta penosa! Prepara a distante viagem por todos os meios. Faz tudo que for necessário para teu maior desejo e acabarás por conseguir. Não sejas mais homem senão para outrem, renuncia a sê-lo para ti mesmo! Para ti não há mais felicidade a não ser em ti, por tua arte. Oh Deus, dá-me força de me vencer! (FAUCONNIER, 2012, p. 131).
\end{abstract}

Apesar dos percalços pelos quais Beethoven passou - os quais encontram ressonância nas histórias de inúmeras pessoas - também os aspectos amorosos fizeram parte de sua vida. Recordo-me de que, na ocasião da oficina que ministrei, ter comentado a respeito com os participantes. São conhecidos muitos nomes das chamadas "amadas de Beethoven", sendo, inclusive, tema de produções cinematográficas. Muitas das mulheres por quem Beethoven se apaixonou figuraram imortalizadas em suas obras, como Julie Guiccardi, Therese e Josephine Von Brunswick, Bettina Brentano e outras, cuja paixão do solitário músico inspirava mais compaixão que, verdadeiramente, amor. Conhecida é a carta supostamente endereçada à amada imortal de Beethoven, cuja identidade ainda é uma incógnita. Mas, nunca foi entregue. Datada de 6 julho de 1812, é de rara beleza. Eis alguns trechos:

Meu anjo, meu tudo, meu próprio ser! (...) Podes mudar o fato de que és inteiramente minha e eu inteiramente teu? (...) Só contemplando nossa existência com olhos atentos e tranquilos, podemos atingir nosso objetivo de viver juntos. (...) Continua a me amar, não duvida nunca do fidelíssimo coração de teu amado L., eternamente teu, eternamente minha, eternamente nossos. (NOVA CULTURAL, 1988, p. 28).

Em relação a Beethoven vale, também, mencionar duas outras particularidades, em relação à sua produção musical. Tanto a natureza quanto a vida política permearam sua inspiração criadora. Exemplo de composição que enfoca a natureza é a Sinfonia ${ }^{\circ} 6$, em Fá Maior, Op. 68, denominada de "Pastoral". Escrita em 1808 e publicada em 1809, foi dedicada ao Príncipe von Lobkowitz e ao Conde Rasumowsky, sendo estruturada em 
cinco movimentos ${ }^{3}$. Conforme seus biógrafos, Beethoven teve por propósito descrever a sensação experimentada nos ambientes rurais. Ele insistia que essas obras não deveriam ser interpretadas como um "quadro sonoro", mas como uma expressão de sentimentos. As denominações dos movimentos da sinfonia dão uma dimensão do que trata a obra:

$1^{\circ}$ Movimento: Allegro ma non troppo. Despertar das emoções alegres ao chegar no campo.

$2^{\circ}$ Movimento: Andante molto mosso. Representando a Cena à margem de um riacho.

$3^{\circ}$ Movimento: Allegro. Reunião alegre dos camponeses.

$4^{\circ}$ Movimento: Allegro. Representando a tempestade.

$5^{\circ}$ Movimento: Allegretto. Canto dos Pastores. Regozijo geral. Ação de graças ao Senhor, depois da tempestade. (PINTO, s/d, p. 188).

Cabe salientar que esta sinfonia procurou traduzir, através da música, uma espécie de cenário. Esta foi uma das propostas dos compositores contemporâneos de Beethoven. A este tipo de composição denomina-se de música programática (BENNETT, 1985).

Com aproximadamente 26 anos de idade, Beethoven começou a apresentar os primeiros sintomas de uma surdez que, posteriormente, o tornaria totalmente surdo. Apesar de caros, longos e demorados tratamentos, percebeu que não haveria cura. $\mathrm{O}$ compositor, aos poucos, foi se afastando do convívio social, tornando-se cada vez mais solitário e introspectivo (RIBEIRO, 1965).

Embora com todos esses problemas, é intrigante observar que a última obra de Beethoven, a Sinfonia ${ }^{\circ}$ 9, em Ré Menor, Op. 125 - também conhecida como "Nona Sinfonia" ou "Sinfonia Coral" - foi composta quando ele estava completamente surdo, o que ocorreu entre os anos de 1817 e 1823, na terceira e última fase do compositor. Esse fato demonstra, de certo modo, a força interior presente na vida de Beethoven. Força esta que o acompanhou desde os tempos da infância, quando dos problemas com seu pai, até o acometimento de sua surdez. Dedicada ao Rei Friedrich Wilhelm $3^{\circ}$, da Prússia, a composição é formada de quatro movimentos, quais sejam:

$1^{\circ}$ Movimento: Allegro ma non troppo, um poço maestoso.

$2^{\circ}$ Movimento: Molto vivace. Molto vivace presto (scherzo).

$3^{\circ}$ Movimento: Adagio molto e cantabile; andante moderato.

\footnotetext{
3 Movimento pode ser explicado como "parte auto-suficiente de uma composição instrumental extensa, como uma sinfonia ou sonata" (ZAHAR, 1985, p. 248).
} 
$4^{\circ}$ Movimento: Presto, presto allegro assai, allegro assai vivace (allá márcia). Andante maestoso. Adagio ma non troppo, ma divoto. Allegro enérgico sempre bem marcato. Prestíssimo. (PINTO, s/d, p. 194).

Todos os movimentos desta fenomenal obra são de grande beleza. Sublinha-se, todavia, o $4^{\circ}$ movimento, pois, além de ser muito conhecido, por figurar em propagandas, celulares e jogos de computador e da Internet, traz uma dimensão de superação da surdez, por parte de Beethoven. O compositor introduziu vozes humanas em sua sinfonia, algo, até então, nunca realizado. O texto entoado pelo coro, uma ode ${ }^{4}$ de Schiller, dá uma dimensão da grandiosidade da composição. A seguir, encontra-se a primeira estrofe da Ode à Alegria, da Sinfonia ${ }^{\circ}$ 9, em Ré Menor, Op. 125, cuja tradução é devida a Tasso da Silveira, de acordo com dados de 1945, de Rodolfo Josetti (PINTO, s/d).

Oh! Júbilo, centelha clara e ardente do divino fulgor, luz essencial! Ébrios do teu clarão onipotente, penetramos em teu santuário ideal. Une-se ao teu prestígio, novamente, tudo o que separou, na vida, o mal. De novo os homens trêmulos se irmanam ao resplendor de tua chama celestial! (PINTO, s/d, p. 198).

Para conhecermos a obra composicional de Beethoven, eis uma sugestão de escuta, incluindo sonatas, sinfonias, quartetos e concertos, que pode organizar a apropriação de sua música:

Sonatas: Sonata Patética, Op. 13 (1789); Sonata em si bemol maior, Op. 22 (1800); Sonata ao Luar, Op. 27 (1801); Sonata em lá bemol maior, Op. 26 (1801); Sonata para violino e piano em dó menor, Op. 30 (1802); Sonata Apassionata, Op. 57 (1804).

Sinfonias: Sinfonia Número 3 em mi bemol maior (1803); Sinfonia Número 5 em dó menor (1807); Sinfonia Número 6 em fá maior (1808); Sinfonia Número 7 em lá maior (1811); Sinfonia Número 9 em ré menor (1823).

Quartetos: Quarteto em mi bemol maior, Op. 127 (1824); Quarteto em lá menor, Op. 132 (1825).

Concertos: Concerto para piano e orquestra número 5, Op. 73 (1809); Concerto número 3, Op. 37 (1800). (COLEÇÃO FOLHA DE MÚSICA CLÁSSICA, 2022).

\footnotetext{
${ }^{4}$ Ode é uma forma poética de origem grega, com variação constante de métrica e ritmo. É frequentemente endereçada a um rei ou divindade (ZAHAR, 1985, p. 265).
} 
Beethoven foi um compositor muito importante, não somente no momento em que viveu, mas seu legado perdura até a atualidade. Para ele, a música era a revelação

[...] de uma verdade superior e o músico deveria ser o profeta de um novo tempo. Ele não se curvaria ao tempo, mas o tempo a ele. Assim, a rebeldia beethoveniana não foi acidente de percurso ou mera questão de temperamento - foi um gesto consciente de afirmação e insatisfação. Ninguém tinha ainda avaliado o quanto a arte deve à inquietação, ao inconformismo, ao sofrimento. Impondo sua música como um valor superior dentro da sociedade para além de suas funções imediatas, decorativas e utilitárias, Beethoven deixou uma arte que permanecerá como eloquente testemunha das capacidades criadoras de nossa civilização. (LOPEZ, 1995, p. 209).

A partir da apresentação de algumas particularidades da vida e da obra de Bach e Beethoven, apresenta-se, de modo abrangente, a oficina oferecida aos professores da RME-POA/RS.

\section{A Oficina}

A oficina, ofertada a professores da RME-POA/RS, ocorreu, como dito, em uma noite de 12 de junho, há alguns anos atrás, nas dependências da SMED-POA/RS. Teve a duração de três horas, sendo organizada em quatro momentos. Cerca de 30 professores participaram da oficina, incluindo homens e mulheres, de diversas idades, cujas formações variaram nas diversas áreas do conhecimento, inclusive a música, porém, todos com uma formação universitária em licenciatura. Percebe-se, portanto, que não havia a obrigatoriedade de possuírem conhecimentos musicais prévios.

O momento inicial da oficina foi destinado à apresentação da proposta, sendo submetida à aprovação dos participantes, objetivando-se a realização de um trabalho democrático e coletivo. Estabelecidas e combinadas as bases da oficina, a qual foi acrescida de algumas contribuições interessantes sobre materiais adicionais a serem compartilhados com os participantes, passou-se ao segundo momento, que foi uma sensibilização, caracterizado pela apreciação de duas obras musicais.

Nesta apreciação musical foram realizadas duas audições, sendo a primeira a Tocata e Fuga em Ré Menor, BWV 565, e a segunda Für Elise, Bagatelle n. ${ }^{\circ} 25$ em Lá menor (WoO 59 Bia 515), de Bach e Beethoven, respectivamente. Não foi revelado aos 
participantes, de início, os nomes das músicas, tampouco os compositores. Deixou-se, inicialmente, uma escuta livre. Para tanto, a fim de ser mais prazerosa, solicitou-se que os participantes encontrassem uma posição confortável no local, a fím de atentar adequadamente à música.

Após, passou-se às reflexões e comentários sobre as escutas das obras, incentivando os participantes a falarem sobre o que sentiam ou pensavam a partir das audições. Esta é uma atividade muito importante, e permite um engajamento ativo com a música. Conforme França e Swanwick (2002):

O ouvir permeia toda experiência musical ativa, sendo um meio essencial para o desenvolvimento musical. É necessário, portanto, distinguir entre o ouvir como meio, implícito nas outras atividades musicais, e o ouvir como fim em si mesmo. No primeiro caso, o ouvir estará monitorando o resultado musical nas várias atividades. No segundo, reafirma-se o valor intrínseco da atividade de se ouvir música enquanto apreciação musical. (FRANÇA; SWANWICK, 2002, p. 12).

Procurou-se, portanto, ao mesmo tempo em que ponderávamos sobre as audições, também pontuávamos o valor deste tipo de atividade que, efetivamente, é educação musical. É “uma forma legítima e imprescindível de engajamento com a música. Através dela podemos expandir nossos horizontes musicais e nossa compreensão" (FRANÇA; SWANWICK, 2002, p. 12).

Em seguida, ao revelar os nomes das músicas e seus compositores, passou-se à contextualização acerca de suas vidas e obras. Destaca-se que, ao indagar se alguém conhecia uma ou as duas composições, muitas pessoas revelaram conhecê-las. A totalidade dos participantes conhecia Für Elise, Bagatelle n. ${ }^{\circ} 25$ em Lá menor (WoO 59 Bia 515), de Beethoven. A grande maioria conhecia a Tocata e Fuga em Ré Menor, BWV 565 , de Bach. O fato de conhecerem as composições não foi uma surpresa sendo, inclusive, um dos motivos da escolha destas. Objetivava-se, a partir de músicas conhecidas pela maioria das pessoas, realizar um trabalho com os aspectos da vida e da obra dos músicos e, assim, fazer uma conexão com a diversidade musical, focando a música clássica e a cultura experiencial, oferecendo uma plataforma educativa, aclarando o sentido e os mecanismos através dos quais exerce a ação da influência sobre as novas gerações (PÉREZ GÓMEZ, 2001). 
Ao fazer a contextualização acerca dos compositores e suas obras, atividade que integra a proposta de Swanwick (2003), como experiência de complemento literáriomusical, realizou-se a vivência centrada na apreciação, de modo bastante ativo e engajado. A seguir, ao se tratar da vida de ambos os compositores, bem como dos fatos de suas vidas, foram visíveis as reações de identificação com a realidade que os participantes viviam em seus cotidianos, tanto na sala de aula, com seus alunos, quanto em suas próprias vidas. Neste momento da oficina não foram poucos os casos relatados de alunos que tinham problemas de visão, de audição, que tinham problemas familiares, sendo, muitas vezes, espancados por membros da família, problemas com álcool, drogas, enfim, houve uma grande identificação, um acesso à potencialidade autotransformativa (BACH JÚNIOR, 2019).

Deve-se lembrar, contudo, que o propósito da oficina era trabalhar na perspectiva da educação musical, e não fazer uma catarse terapêutica, ou algo semelhante, até porque não se tem formação profissional para isso, tampouco o propósito era esse. Objetivavase, isso sim, estabelecer uma conexão entre as músicas, os compositores e, assim, encantar os participantes quanto à música clássica e as particularidades da história da música, fazendo um trabalho pedagógico-musical.

Pareceu que o resultado atendeu às expectativas. Com satisfação foi possível finalizar este momento, a partir da escuta de dois exemplos musicais, de cada uma das obras, mas agora, nas versões para Rock (versão Metal) e Funk. Estes exemplos musicais podem ser, atualmente, encontrados com muita facilidade na Internet, por meio do YouTube ou de outros locais virtuais. Essa é uma das vantagens da atualidade. Foram muito interessantes, também, neste momento, os comentários dos participantes, bem como o sentimento de identificação por eles demonstrado. Houve uma aproximação entre o mundo acadêmico e o cotidiano dos participantes. E, assim, foi possível passar para o próximo momento da oficina, quando colocaríamos em prática os aprendizados.

O terceiro momento da oficina foi destinado à prática teórico-reflexiva, com vistas à elaboração de uma proposta (um esboço, posto que o tempo da oficina foi limitado para uma grande elaboração) que contemplasse a inserção de elementos da música clássica e da história da música em um planejamento. Esta atividade foi realizada em grupos, pois, entende-se a importância do trabalho coletivo na escola, o que resulta bons e perenes corolários para o ensino e aprendizado para todos e, em especial, para os alunos. E assim ocorreu. As propostas oriundas dos participantes, em grupos, trouxeram diversos outros 
compositores, igualmente conhecidos, ou ao menos, com muitas músicas do conhecimento das pessoas, como Mozart, Vivaldi, Haendel, Chopin, Villa-Lobos, Carlos Gomes, entre outros. Vários participantes sabiam particularidades da vida e da obra de muitos deles, o que foi muito interessante e, de certo modo, desconstrói uma concepção disseminada de que a música clássica encontra-se distante das pessoas, sendo "de elite". Discorda-se desta premissa, pois, muitas das músicas que a população escuta, nos mais diversos meios de comunicação, também incluem este tipo de música. Profusas músicas clássicas se encontram em redes sociais, na mídia, e em diversos jogos, por exemplo.

O quarto momento, e final, foi destinado ao compartilhamento das propostas criadas pelos grupos e aos respectivos comentários, que trouxeram as possibilidades e os limites das propostas, sugestões de melhorias, enfim, diversas falas, não somente de quem ministrava a oficina, mas, fundamentalmente, dos participantes, demonstrando que o conhecimento compartilhado é melhorado e, assim, solidifica-se.

Foi, também, uma oportunidade para realizar uma parte sempre muito importante em qualquer prática educacional, que é a da avaliação. Assim, foi-lhes solicitado que avaliassem a oficina e, principalmente, apontassem melhorias e sugerissem desdobramentos. Concorda-se com Sordi e Ludke (2009), que preconizam a importância da avaliação, pois esta

[...] precisa ser elevada à condição estratégica nos processos de formação docente, sejam eles iniciais ou permanentes, e isso inclui o exercício da autoavaliação e a avaliação pelos pares. Um professor familiarizado com estas práticas ganha condição de bem ensinar e bem realizar a avaliação de/com seus estudantes. Assim como compreenderá, com algum prazer, que lhe cabe o direito/dever de participar de processos de avaliação da escola em que trabalha, coresponsabilizando-se pelo desenvolvimento do seu projeto pedagógico. (SORDI; LUDKE, 2009, p. 317).

Foram sugeridas melhorias muito interessantes, como, por exemplo, a inclusão de algum momento para a realização musical, quer seja cantando ou a partir de criações com instrumentos musicais alternativos. Outra sugestão que surgiu, relacionou-se à solicitação de que fosse criado um grupo ou um fórum permanente destinado à realização de encontros sistemáticos para tratar da música na escola e as possibilidades de inclusão dos diversos conteúdos, como a música clássica, popular, e folclórica, em diversos gêneros. 
Entende-se que, pela adesão e resultados da oficina, tenha sido possível alcançar, e com êxito, o objetivo proposto.

\section{Considerações Finais}

Por fim, após o que foi apresentado e discutido a respeito da vida e da obra dos dois compositores, Bach e Beethoven, na realização da oficina, salienta-se a riqueza da utilização do material musical presente no cotidiano, quer seja na mídia ou em outros

veículos, e inserido em diversos momentos históricos. A incorporação da história da música aos conteúdos da escola, através das obras e fatos da vida dos diversos compositores, pode transversalizar com o cotidiano e, acima de tudo, potencializar o aprendizado em sala de aula.

Talvez, assim, um conceito possa ser desnaturalizado (MEDEIROS, 2006), o de que a música erudita está distante das pessoas, sendo um conhecimento inútil e desnecessário ao trabalho educativo. Ao contrário, o conhecimento oriundo do trabalho com a música, em seus diversos períodos históricos, pode auxiliar na construção de conhecimentos como um todo e, inclusive, na construção de nossos alunos como cidadãos atuantes da sociedade!

\section{REFERÊNCIAS}

BACH JÚNIOR, Jonas. O trabalho biográfico como fonte de aprendizado: autoeducação e fenomenologia de Goethe. Educar em Revista, Curitiba, Brasil, v. 35, n. 74, p. 233-250, mar./abr. 2019. Disponível em: <https://www.scielo.br/j/er/a/LrddbFRkFnJzSfXYkymzvXC/?lang=pt\&format=pdf>. Acesso em: 20 jan. 2022.

BENNETT, Roy. Uma breve história da música. Rio de Janeiro: Zahar, 1985.

COLEÇÃO FOLHA DE MÚSICA CLÁSSICA. Disponível em: <https://musicaclassica.folha.com.br>. Acesso em: 20 jan. 2022.

FAUCONNIER, Bernard. Beethoven. Porto Alegre: L\&PM, 2012.

FRANÇA, Cecília Cavalieri; SWANWICK, Keith. Composição, apreciação e performance na educação musical: teoria, pesquisa e prática. Em Pauta, v. 13, n. 21, p. 5-41, dez. 2002. Disponível em: <https://seer.ufrgs.br/EmPauta/article/view/8526/4948>. Acesso em: 20 jan. 2022.

FREIRE, Vanda Lima Bellard. A História da Música em Questão: Uma Reflexão Metodológica. Revista Música, [S. 1.], v. 5, n. 2, p. 152-170, 1994. Disponível em: 
<https://www.revistas.usp.br/revistamusica/article/view/55079>. Acesso em: 19 jan. 2022.

GAGO, Luis Carlos. Bach. Madri: Alianza Editorial, 1995.

GALWAY, James. A música no tempo. Tradução de Alexandre Soares Carneiro e Maria Estela Heider Cavalheiro. São Paulo: Martins Fontes, 1987.

KENNEDY, Michael. The Oxford dictionary of music. Oxford University Press (UK), 6th ed., 2013.

LOPEZ, Luiz Roberto. Sinfonias e catedrais: representação da história na arte. Porto Alegre: Ed. da Universidade, 1995.

MEDEIROS, Marilu Fontoura de. Um pouco de ar fresco: singularidades, experimentações e experimentações no presente. Porto Alegre: Prefeitura Municipal/Secretaria Municipal de Educação, 2006.

MIRANDA C., Marcelo. La enfermedad de Johann Sebastian Bach y su mediático médico inglês. Rev. Med. Chile, 2019, v. 147, n. 3, p. 356-360. Disponível em: $<$ https://www.scielo.cl/pdf/rmc/v147n3/0717-6163-rmc-147-03-0356.pdf > . Acesso em: 20 jan. 2022.

MOJOLA, Celso. O futuro da música clássica: perspectivas para as próximas décadas. Revista Eletrônica Thesis, São Paulo, ano. XIV, n. 28, p. 60-70, 1º sem 2018. Disponível em: 〈http://www.cantareira.br/thesis2/ed_28/materia3.pdf > Acesso em: 20 jan. 2022.

NOGUEIRA, Marcos Pupo. Porque estudar música erudita. In: JORDÃO, Gisele et. al. A música na escola. Brasília: Allucci \& Associados Comunicações, 2012, p. 122-123.

NOVA CULTURAL. Clássica: a história dos gênios da música. São Paulo: 1988.

PÉREZ GÓMEZ, Ángel. I. A cultura escolar na sociedade neoliberal. Tradução de Ernani da Fonseca Rosa. Porto Alegre: ARTMED, 2001.

PINTO, Cesar. A divina música ao alcance de todos. Rio de Janeiro: Edição do Autor, s/d.

RIBEIRO, Wagner. Folclore musical volume II: história da música no antigo continente. São Paulo: Editora FTD, 1965.

SORDI, Mara Regina Lemes de; LUDKE, Menga. Da avaliação da aprendizagem à avaliação institucional: aprendizagens necessárias. Avaliação, Campinas; Sorocaba, SP, v. 14, n. 2, p. 267-290, jul. 2009. Disponível em:

<https://www.scielo.br/j/aval/a/7zM7wf5Zw6wxrK8LTbwpWJq/?lang=pt > . Acesso em: 20 jan. 2022.

SWANWICK, Keith. Ensinando música musicalmente. São Paulo: Moderna, 2003. 
ZAHAR. Dicionário de música. Rio de Janeiro: Zahar Editores, 1985.

Recebido em: 03/01/2022

Aprovado em: 30/01/2022

Publicado em: 03/02/2022 